\title{
PENGARUH KUALITAS PELAYANAN TERHADAP LOYALITAS PELANGGAN RESTORAN QUICK CHICKEN JALAN JAWA NO. 63 JEMBER TAHUN 2016
}

\author{
Ilham Akbar Solichin ${ }^{1}$, Sri Kantun ${ }^{1}$, Bambang Suyadi ${ }^{1}$ \\ ${ }^{1}$ Program Studi Pendidikan Ekonomi, Fakultas Keguruan dan Ilmu Pendidikan, Universitas Jember
}

\begin{abstract}
This study was conducted to know the significant influence of service quality (reliability, responsiveness, assurance, empathy, and tangible) toward customer loyalty (re-purchase, words of mouth recommendations, and immune to the pull of a competitors) in Quick Chicken restaurant Jalan Jawa No. 63 Jember. The determination of research location use purposive area method, whereas the determination of sample use purposive sampling method. Data collection method use questionaires, documents, interviews and observation. Data analysis used in this study is inferential analysis consist of simple linear regression, the regression line variance, the F-test, and the effectiveness of regression line. The research result shows that a simple linear regression analysis forms a equation $\mathrm{Y}=6.438+0,126 \mathrm{X}$ with a value of Rsquare is 0.694 , Fchange value is 176.576, Ftable value is 3.96 on level of significance testing criteria is 0.05 with Fchange $>$ Ftable, so Ho is rejected, and if $\operatorname{sig}<\alpha$, and then Ho denied. It shows that the quality of service has significant influence toward customer loyalty in restaurant Quick Chicken Jalan Jawa No. 63 Jember with total of significance influence is $69.4 \%$, but the balance of $30.6 \%$ influenced by other variables that don't examined. The suggestion that can be given for management of Quick Chicken restaurant Jalan Jawa No. 63 Jember is expected to always keep the service quality and always have tactics to improve the service quality for all of its customers because they are able to retain customers.
\end{abstract}

Keywords: Service Quality, Customer Loyalty, Restaurant, Franchise, Quick Chicken

\section{PENDAHULUAN}

Perkembangan usaha kuliner saat ini telah menunjukkan kemajuan yang pesat. Seiring dengan perkembangan tersebut, semakin banyak para pelaku usaha mendirikan usaha kuliner dalam berbagai bentuk mulai dari pedagang kaki lima, warung, rumah makan, hingga restoran waralaba (franchise). Banyaknya restoran franchise dengan konsep fast food yang berdiri di Kabupaten Jember membuat para pelaku usaha franchise (franchisee) bersaing dengan restoran franchise dengan konsep fast food yang lain. Persaingan tersebut menuntut para pelaku bisnis untuk mampu memaksimalkan kinerjanya agar dapat memenangkan persaingan bisnis. Untuk memenangkan persaingan bisnis maka restoran franchise harus tetap menjaga kualitas pelayanannya.

Kualitas pelayanan menjadi salah satu faktor utama yang harus diperhatikan karena merupakan kunci menentukan keberhasilan usaha. Wyckop mengatakan bahwa (dalam Tjiptono, 2008:59) pelayanan dapat dikatakan berkualitas jika mampu memposisikan seluruh pelanggan sebagai raja yang harus dilayani dengan baik sesuai keinginan dan harapannya. Kualitas pelayanan dapat diukur menggunakan pemahaman mengenai lima dimensi kualitas pelayanan menurut Tjiptono (2007: 43) yaitu keandalan (reliability), daya tanggap (responsiveness), jaminan (assurance), empati (emphaty), dan bukti fisik (tangible). Oleh karena itu, franchisee restoran perlu memiliki karyawan yang berpengetahuan yang baik sesuai dengan tugasnya mulai dari pelayan, kasir, hingga koki atau juru masak (Tjiptono, 2011:198). Karyawan yang memahami tugasnya diharapkan bisa merespon semua keluhan dari pelanggan tanpa terkecuali dan menyajikan menu pesanan pelanggan dengan cepat (Rangkuti, 2002:30). 
Selain itu, franchisee juga perlu untuk memberikan rasa percaya pada para pelanggan. Kepercayaan pelanggan dapat terbentuk apabila franchisee memberikan jaminan tertentu mulai dari jaminan mutu produk yang ditawarkan hingga jaminan kebersihan baik didalam ruangan maupun diluar ruangan restoran, sehingga pelanggan merasa aman karena tidak memiliki perasaan ragu-ragu ketika melakukan pembelian (Tjiptono, 2011:346). Pendekatan pribadi karyawan juga berperan penting untuk menarik empati pelanggan (Tjiptono, 2011:347). Pihak restoran juga perlu memberikan kenyamanan kepada pelanggan dengan menyediakan fasilitas, sarana, dan prasarana yang baik (Tjiptono, 2007:273).

Meskipun demikian, banyak restoran franchise yang kurang memerhatikan kualitas pelayanan yang diberikan kepada pelanggan, seperti memerlukan waktu yang sangat lama untuk menyajikan makanan dan minuman yang disebabkan oleh banyaknya pesanan menu yang diterima, tidak segera membersihkan meja makan setelah pelanggan selesai menyantap hidangan dan meninggalkan tempat sehingga jika ada pelanggan lain datang dan menempati meja tersebut tentunya merasa tidak nyaman karena meja tersebut masih dalam keadaan kotor, ketidaksesuaian menu yang dipesan pelanggan dengan menu yang diantarkan, dan sempitnya lahan parkir yang diberikan sehingga pelanggan yang datang kesulitan untuk memarkirkan kendaraannya. Beberapa kesenjangan tersebut menyebabkan pelanggan kurang memiliki loyalitas yang kuat, sehingga besar kemungkinan mereka sekali-kali membeli ke restoran franchise alternatif yang lain walaupun makanan dan minuman yang ditawarkan tidak sesuai dengan ekspektasi mereka.

Semua dimensi kualitas pelayanan harus benar-benar diperhatikan dengan baik untuk mempertahankan para pelanggan yang telah puas sehingga dapat membuat pelanggan menjadi setia. Loyalitas pelanggan merupakan bagian terpenting yang harus diperhatikan pelaku usaha restoran franchise karena memiliki korelasi yang positif dengan keberlangsungan hidup dari bisnis yang dikelola dan dapat menarik pelanggan baru (Griffin, 2005). Pelanggan yang memiliki loyalitas yang kuat akan selalu melakukan pembelian ulang secara teratur, merekomendasikan serta mengatakan hal-hal positif restoran tersebut kepada siapa saja yang dikenal, dan kebal terhadap tarikan dari pesaing (Griffin, 2005:22).

Dasar bagi loyalitas sejati terletak pada kualitas pelayanan yang menjadi input utamanya (Lovelock et al, 2013:91). Semakin restoran franchise fast food mengetahui kebutuhan, keinginan, dan harapan pelanggan, maka akan semakin besar pula kemungkinan restoran tersebut akan memberikan pelayanan yang semakin sesuai dengan ekspektasi pelanggan, dan semakin restoran Quick Chicken melayani pelanggan sesuai dengan ekspektasinya, maka pelanggan tersebut akan memiliki ikatan loyalitas yang kuat. Oleh karena itu, semakin baik kualitas pelayanan maka akan mempengaruhi loyalitas pelanggan yang telah puas (Mulyono $\mathrm{dkk}, 2007)$.

Quick Chicken merupakan salah satu restoran franchise dengan konsep fast food yang memiliki menu utama yaitu fried chicken. Restoran ini juga merupakan restoran franchise dalam negeri yang memiliki lebih dari 360 gerai yang terebar di seluruh Indonesia dan memiliki 4 gerai yang tersebar di Kabupaten Jember.

Pada pengamatan awal di restoran Quick Chicken di Kabupaten Jember berada di Jalan Jawa No. 63, Kecamatan Sumbersari diketahui bahwa restoran tersebut sudah memberikan pelayanan yang baik yang ditunjukkan keramahan para karyawan restoran saat melayani 
pembeli, menyajikan makanan dan minuman kepada pembeli secara cepat, menjaga kebersihan baik di dalam maupun di luar ruangan. Kualitas pelayanan restoran ini juga terlihat dari kondisi di dalam ruangan juga nyaman dengan desain interior dan eksterior yang menarik Pihak pengelola restoran juga menyediakan fasilitas, sarana dan prasarana yang baik, seperti tersedianya kamar mandi dan area parkir yang memadai. Selain itu, pengunjung restoran ini terlihat nyaman saat menyantap hidangan yang dipesannya baik di dalam maupun di luar restoran. Semua itu menjadi alasan tersendiri bagi pelanggan untuk kembali datang untuk membeli makanan dan minuman di restoran tersebut karena sudah merasa puas dengan pelayanan yang diterima.

Berdasarkan uraian pendahuluan tersebut, maka penelitian ini berjudul "Pengaruh Kualitas Pelayanan Terhadap Loyalitas Pelanggan Restoran Quick Chicken Jalan Jawa No. 63 Jember Tahun 2016".

\section{METODE PENELITIAN}

Penelitian ini menggunakan pendekatan kuantitatif non eksperimental. Berdasarkan teknik pengumpulan data, penelitian ini menggunakan data primer yang diperoleh melalui metode angket, wawancara, dokumen, dan observasi. Metode angket diperoleh secara langsung dari pelanggan restoran Quick Chicken dengan cara menyebarkan kuesioner dengan 24 buah pertanyaan yang harus dijawab oleh responden. Sumber data primer lain pada penelitian ini juga diperoleh melalui wawancara dengan pemilik restoran Quick Chicken dan dokumen yang meliputi struktur organisasi, standarisasi pelayanan, dan jumlah pembeli.

Penentuan populasi dalam penelitian ini adalah seluruh konsumen restoran Quick Chicken yang berjumlah 400 orang. Metode pengambilan sampel menggunakan teknik purposive sampling dengan kriteria responden harus berumur lebih dari 16 tahun dan pernah melakukan pembelian ulang lebih dari dua kali. Teknik penentuan jumlah responden merujuk pada pendapat Roscoe (dalam Neolaka, 2014:82) yang mengatakan bahwa jumlah sampel minimal penelitian korelasional adalah 30. Peneliti juga merujuk pada rumus penentuan ukuran sampel menurut Umar (2003:146), sehingga diperoleh 80 responden. Selanjutnya data yang diperoleh menggunakan metode angket diolah dengan proses editing, scoring, dan tabulasi. Hasil angket yang diperoleh dilakukan uji validitas dan uji reliabilitas dengan menggunakan software SPSS 22.0. Analisis data pada penelitian ini juga menggunakan analisis inferensial dengan bantuan software SPSS 22.0 yang terdiri dari regresi linier sederhana, analisis varian garis regresi, uji serentak (Uji F), dan efektifitas garis regresi.

\section{HASIL DAN PEMBAHASAN}

\section{Hasil Penelitian}

Berdasarkan analisis data yang telah dilakukan, diperoleh hasil analisis garis regresi linier sederhana seperti pada tabel berikut:

Tabel 1. Ringkasan Uji F, Multiple R, dan R Square.

\begin{tabular}{|c|c|c|c|c|c|c|}
\hline Variabel & F Change & Ftabel & $\begin{array}{c}\text { Sig. F } \\
\text { Change }\end{array}$ & $\boldsymbol{A}$ & $\mathbf{R}$ & $\mathbf{R}_{\text {Square }}$ \\
\hline X terhadap Y & 176,57 & 3,96 & 0,000 & 0,05 & 0,833 & 0,694 \\
\hline
\end{tabular}

Sumber: Data diolah 2017 
Tabel diatas menunjukkan bahwa nilai koefisien korelasi sebesar 0,833, artinya nilai tersebut menunjukkan bahwa hubungan variabel kualitas pelayanan terhadap loyalitas pelanggan dikategorikan memiliki hubungan yang sangat kuat. Nilai $F_{\text {hitung }}=176,576$, nilai $\mathrm{F}_{\text {tabel }}=2,34$ dengan tingkat signifikansi $\mathrm{F}=0,000$, maka nilai $F_{\text {hitung yang berjumlah } 176,576}$ lebih besar daripada niai $\mathrm{F}_{\text {tabel }}$ yaitu 3,96 dan tingkat signifikansi juga lebih kecil daripada 0,05, sehingga dapat diambil suatu keputusan bahwa ada pengaruh yang signifikan dari kualitas pelayanan terhadap loyalitas pelanggan restoran Quick Chicken jalan Jawa No. 63 Jember tahun 2016. Sedangkan besaran persentase pengaruh kualitas pelayanan terhadap loyalitas pelanggan dihitung menggunakan rumus $\mathrm{R}_{\text {square }} \mathrm{x} 100 \%=0,694 \times 100 \%=69,4 \%$

\section{Pembahasan}

Hasil penelitian membuktikan bahwa kualitas pelayanan memiliki pengaruh yang signifikan terhadap loyalitas pelanggan restoran Quick Chicken Jalan Jawa No. 63 Jember tahun 2016.

Kualitas pelayanan restoran Quick Chicken dalam hal bukti fisik sangat berpengaruh terhadap loyalitas pelanggan. Hal ini ditunjukkan oleh sebagian besar pelanggan memberikan penilaian bahwa kondisi penerangan ruangan sangat terang, Air Conditioner dan kipas angin juga selalu membuat para pelanggan yang berada didalam ruangan merasa sejuk dan nyaman, perlengkapan makan dan termasuk kursi dan meja yang digunakan selalu bersih dan bebas dari kecacatan. Selain itu, karyawan juga selalu mengenakan pakaian dengan bersih, rapi, dan sering berganti-ganti seragam. Hal tersebut tentu sangat membuat para pelanggan merasa senang. Pelanggan juga dapat memarkirkan kendaraan yang dibawa dengan mudah, karena restoran Quick Chicken menyediakan lahan parkir yang dapat menampung jenis kendaraan bermotor baik mobil maupun sepeda motor.

Bentuk pelayanan berkualitas yang diberikan oleh restoran Quick Chicken dalam hal bukti fisik tersebut dapat memberikan rasa nyaman sehingga hal ini dapat menjadi alasan pelanggan menjadi loyal. Hal tersebut juga telah sesuai dengan pendapat Tjiptono (2007:273) yang mengatakan bahwa kenyamanan pelanggan akan dapat membuat pelanggan menjadi setia bila fasilitas, sarana, prasarana, dan hingga penampilan fisik seluruh karyawan unit usaha mampu memenuhi ekspektasi pelanggan.

Faktor lain yang memengaruhi loyalitas pelanggan adalah daya tanggap. Sesuai dengan konsep restoran Quick Chicken yaitu fast food, cepatnya pelayanan restoran Quick Chicken dalam melayani pelanggan sudah tidak diragukan lagi karena secara umum para pelanggan menilai bahwa waktu yang dibutuhkan untuk menerima menu yang dipesan kurang dari lima belas menit. Cepatnya pelayanan tersebut sangat mendapat apresiasi yang baik dari para pelanggan. Meskipun demikian, ada beberapa pelanggan yang menilai bahwa terkadang pelayanan restoran Quick Chicken dinilai kurang cepat karena disebabkan oleh banyaknya pelanggan lain yang melakukan pesanan namun mereka tidak terlalu mempermasalahkan hal tersebut sebab para karyawan selalu menanggapi dan menangani keluhan-keluhan pelanggan tersebut.

Restoran Quick Chicken juga dinilai handal dalam memberikan pelayanan kepada pelanggan karena jam buka dan jam tutup restoran Quick Chicken yang tepat waktu. Ketepatan jam buka dan jam tutup restoran tersebut juga dibenarkan oleh salah satu karyawan restoran 
yang mengatakan bahwa restoran Quick Chicken selalu membuka gerai tepat pada pukul 09.00 WIB dan menutup gerai tepat pada pukul $22.00 \mathrm{WIB}$, ketepatan waktu ini disebabkan karena para karyawan telah melakukan persiapan selama kurang lebih satu jam sebelum membuka dan menutup restoran. Hal tersebut tentu sejalan dengan pendapat Lupiyoadi (2001:148) yang mengatakan bahwa salah satu alasan kesetiaan pelanggan akan terbentuk usaha yang telah menyampaikan layanan sesuai dengan jadwal yang disepakati.

Selain itu, pelanggan juga telah menilai bahwa kinerja kasir telah tepat dan akurat dalam memberikan nota atau struk pembayaran, memiliki pengetahuan yang baik mengenai komposisi menu makanan dan minuman, dan hafal terhadap varian menu makanan dan minuman yang ada pada daftar menu. Hal tersebut juga telah mendapat konfirmasi dari salah satu karyawan restoran Quick Chicken yang menyatakan bahwa tugas seorang kasir dalam melayani pelanggan harus sesuai dengan standarisasi yaitu memberikan pilihan menu-menu yang telah tertera pada daftar menu, memberikan pelayanan yang akurat dalam hal pemberian nota pembelian dan uang kembalian pelanggan, dan melayani pembelian bila pelanggan memesan menu utama.

Kinerja kasir tersebut juga dibantu oleh para pelayan yang mengantarkan menu pesanan pelanggan. Para pelayan restoran Quick Chicken telah mendapat apresiasi yang baik dari para pelanggan. Apresiasi yang baik tersebut diberikan oleh pelanggan terhadap pelayan yang handal dalam melayani disebabkan karena kinerja pelayan yang jarang melakukan kekeliruan dalam mengantarkan menu yang dipesan oleh pelanggan. Hal ini dibenarkan oleh salah satu karyawan restoran Quick Chicken yang mengatakan bahwa kasir hanya dapat memberikan menu secara langsung bila pelanggan memesan menu utama yaitu fried chicken, namun bila melakukan pemesanan selain daripada menu utama tersebut, maka harus menunggu pelayan mengantarkan ke meja pelanggan.

Restoran Quick Chicken juga dianggap telah mampu mempertahankan pelanggan dengan menarik sikap empati mereka. Pelanggan merasa dihargai saat mereka memasuki restoran dengan sambutan yang diberikan oleh seluruh karyawan. Hal tersebut dibenarkan oleh salah satu karyawan yang memberikan pernyataan bahwa kasir akan memberikan komando sambutan dengan ucapan "selamat pagi (sesuai dengan waktu)" ditempatnya, kemudian seluruh karyawan lain akan menjawab dengan sebuah salam dimanapun posisi karyawan tersebut berada.

Selain itu, pelanggan juga senang dengan sikap karyawan yang sopan dan murah senyum dalam memberikan pelayanan. Walaupun karyawan jarang membukakan pintu masuk, namun pelanggan senang terhadap sikap karyawan karyawan selalu melempar senyum ketika berinteraksi, sehingga hal tersebut dapat menarik empati dan membuat pelanggan tetap setia karena selalu merasa dihargai kedudukannya sebagai raja yang selalu mendapatkan pelayanan yang terbaik.

Selain itu, pelanggan menilai bahwa harga yang tertera pada daftar menu restoran Quick Chicken telah dijamin tepat dan kasir selalu memberikan konfirmasi ketika harga jual dari makanan maupun minuman yang ditawarkan tersebut mengalami perubahan harga. Selain itu, pelanggan tidak ragu-ragu untuk memarkirkan kendaraan yang dibawa karena lokasi parkir telah dijaga oleh juru parkir. Pelanggan restoran Quick Chicken juga telah memberikan apresiasi yang positif dan telah percaya dengan tingkat kebersihan ruangan, karena karyawan selalu menjaga kebersihan dengan menata kembali kursi-kursi yang berserakan setelah 
pelanggan meninggalkan ruangan dan juga membersihkan meja-meja yang kotor. Hal tersebut sesuai dengan pendapat Tjiptono (2007) yang mengatakan bahwa kesetiaan pelanggan juga dapat terbentuk melalui jaminan-jaminan yang diberikan oleh unit usaha.

Restoran Quick Chicken telah berhasil mempertahankan para pelanggannya yang telah puas dengan menjaga kualitas pelayanan yang diberikan. Hal ini, sesuai dengan pendapat Mulyono, dkk (2007) bahwa semakin baik kualitas pelayanan maka akan mempengaruhi loyalitas pelanggan yang merasa puas.

\section{KESIMPULAN DAN SARAN}

\section{Kesimpulan}

Berdasarkan hasil penelitian dan pembahasan yang telah dilakukan maka dapat diambil kesimpulan bahwa kualitas pelayanan memiliki pengaruh yang signifikan terhadap loyalitas pelanggan restoran Quick Chicken Jalan Jawa No. 63 Jember.

\section{Saran}

Berdasarkan kesimpulan dari penelitian ini, maka peneliti dapat memberikan saran kepada beberapa pihak antara lain:

1. Bagi franchisee restoran Quick Chicken Jalan Jawa No. 63 Jember, diharapkan untuk selalu menjaga kualitas pelayanannya dan memiliki kiat-kiat untuk meningkatkan kualitas pelayanan yang diberikan kepada seluruh pelanggannya.

2. Bagi peneliti lain, untuk ikut mempertimbangkan variabel bebas lain yang tidak diteliti pada penelitian ini, seperti lokasi, promosi, kualitas produk, dan lain sebagainya.

\section{DAFTAR BACAAN}

Ghozali, Imam. 2009. Aplikasi Analisis Multivariative Dengan Program SPSS. Edisi Keempat. Semarang: Universitas Diponegoro.

Griffin, Jill. 2002. Customer Loyalty: How to Earn it, How to Keep it. Revision Edition. USA: John Wiley \& Sons, Inc. Terjemahan oleh D. K. Yahya. 2005. Customer Loyalty: Menumbuhkan dan Mempertahankan Kesetiaan Pelanggan. Jakarta: Erlangga.

Mulyono., Hadyanto, B., Yoestini., Nugraheni. Mustofa., K. 2007. Analisis Pengaruh Kualitas Produk Dan Kualitas Layanan Terhadap Kepuasan Konsumen (Studi Kasus Pada Perumahan Puri Mediterania Semarang). Jurnal Studi Manajemen dan Organisasi. 4(2): 91-100.

Neolaka, Amos. 2014. Metode Penelitian dan Statistik. Bandung: PT Remaja Rosdakarya.

Rangkuti, Freddy. 2003. Riset Pemasaran. Jakarta: Gramedia Pustaka Utama.

Tjiptono, F., Chandra., dan Andriani, G., dan Dadi. 2008. Pemasaran Strategik.Yogyakarta: C.V Andi Offset.

Tjiptono, F., Wahyudi, Basuki, S., dan Indro. 2007. Pemasaran Jasa. Cetakan Keenam. Malang: Bayumedia.

Tjiptono, F., dan Chandra. 2011. Service Quality and Satisfaction. Yogyakarta: C.V Andi Offset.

Umar, H. 2003. Metodologi Penelitian Untuk Skripsi Dan Tesis Bisnis. Jakarta: Raja Grafindo Persada. 